Ensaios

Guilherme José da Silva e Sá

$(U n B)$

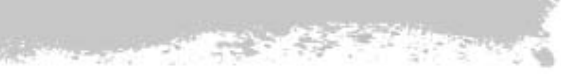

$\left(U_{n} B\right)$

\section{‘Afinal, você é um homem ou é um rato?'”2}

\begin{abstract}
Recusando transportar, como passeante, a língua de um silêncio para outro, o passeante solitário procurará fazer sobretudo incidir esta mais antiga naquela, que é nova, mas como discípulo de São Francisco prefere falar aos pássaros e assim escutar o seu canto.

E assim os animais sempre se calam.

(...) Atingido, pois, o seu cume, essa espécie elimina todas as outras e destrói a Terra, colocada em desequilíbrio e em perigo de morte por essa simplificação e, então, esta última coloca por sua vez a espécie rainha em perigo de extinção pelo seu próprio e excessivo triunfo. Mas se porventura os ratos deixassem de existir, como é que de facto os ratos poderiam continuar a existir apenas entre eles? (Serres 2013: 91-2)
\end{abstract}

Na primeira das três conferências proferidas no Japão em 1986, Claude Lévi-Strauss pontuava a questão candente naqueles dias e cambaleante nos atuais: “O humanismo antropológico será mais capaz que os outros de trazer respostas às interrogações que nos assaltam?" (Lévi-Strauss 2012: 33) Arrebatado por sopros vindos de terras distantes, o célebre antropólogo deslindava que a condição humana não era um ponto (no) pacífico, mas uma reticência que cruzara o Atlântico ${ }^{3}$. Seu questionamento, porém, se impõe nos dias de hoje em função não mais das hordas bárbaras e vândalas de outrora, mas por legiões de não-humanos dispersas em epidemias globais, em publicidade transespecífica, em híbridos destrinchados em ceias natalinas etc.

A convivência com esses não-humanos se não se pode dizer que é nova, ao aceitarmos o argumento da coevolução (Haraway 2003), traz para o palco principal dos debates antropológicos a questão de como, em um intervalo milenar de interações, os animais não-humanos nos fizeram humanos, e como a emergência de um certo humanismo dissociativo cristalizou taxonomias de diferença entre "nós" e "eles" em formas de exploração política, científica e laboral. Em suma, este humanismo é a história de como deixamos de "rir com" e passamos a "rir de", ou de como trocamos o humor pela ironia. Este ensaio é, no entanto, uma tentativa de reversão da ironia humanista por meio do uso de uma dose de sarcasmo animalista. 
Quando iniciei minha pesquisa de doutorado, no ano de 2002, tratar das relações entre seres humanos e animais não era algo que se poderia dizer obtivesse amplo respaldo entre as ciências humanas. Certamente, havia nichos onde falar dos animais era possível ao tratá-los como aqueles seres, quase máquinas, quase pictografias, que compunham bem a paisagem da vida no campo, ou habitando as entreparedes de certo individualismo urbano. A vida desses outros não humanos podia ser um pouco mais animada quando os encontrávamos enredados nos regimes de socialidade indígenas. Parecia que as agências desses não-nós estavam de fato vinculadas as associações com ontologias de alteridade máxima. Os não-humanos só pareciam ser levados a sério entre aqueles cuja própria humanidade era constantemente questionada. Desde então, iniciados num humanismo exclusivista, obtivemos inúmeras respostas para a presença desses estranhos seres que buscavam o nosso convívio social, mas eram alijados de nossa teoria social. Esse contexto estabeleceu as condições de possibilidade para a pergunta que se segue e que, creio eu, será possível redirecioná-la à causa da própria ciência social.

\section{AFINAL, VOCÊ É UM HOMEM OU É UM RATO?}

Vamos por partes, pois esta pergunta nos leva a uma provocação e a um desafio. É possível ser algo nas ciências humanas que não um homem?

A resolução deste enigma leva-nos primeiramente a uma tensão revelada nos seres com gradiente de alteridade humana máximo, representados aqui num modo de existir rato. Ora, ser um rato é algo bem diferente de ser um leão, ou mesmo de ser uma serpente. Ao rato só resta a indesejável sinantropia, sua existência como vetor de doenças, como propagador de impurezas na humanidade. Peste.

“Tout se passe comme si, pour notre inconscient, certains défauts de l'homme ne lui étaient pas consubstantiels mais procédaient d'une véritable contagion par l'animal; au plus simple, ce dernier fournirait le modèle de la conduite" (Thomas 2014:125).

$O$ rato persiste. Os ratos devem ser exterminados. Abjetos objetos. Aqueles que se propagam nas sombras, nas frestas. Praga. Que procriam obscenamente nos redutos. Lumpen. Que se alimentam das sobras. Das sobras da promiscuidade dos outros. Dos outros, homens.

Deduz-se, logicamente, que ser homem e não rato pressupõe a aquisição de elevadas faculdades morais e sanitárias que se opõem a todas aquelas contaminadas pela vida rato. Ser homem é compartilhar estéticas de limpeza, valores como coragem e altivez, é suprimir o desejo irrefreável de desejar a todos os que não são desejados por ninguém, é viver em um mundo onde trafegar sem ser percebido seria algo inadmissível. Ser homem é não ser não humano qual seja o rato. É viver à sombra do homem. Ser rato é ser excluído. Exterminável. Dispensável. Os ratos sobrevivem na não normatividade. Ser rato é resistir. Erráticos.

Espécies companheiras naquilo em que para Haraway (2003) diferem-se dos animais de companhia (pets) por seu caráter indesejável, pois rastejam um ponto de vista humano pressupondo sua adequação a um mundo repleto de ratoeiras - aparato sociotécnico híbrido de gambiarra e desejo, de armadilha e de fome. Como os ciborgues, 
as espécies companheiras são alteridades significantes que devem a sua subsistência à própria realização como entidades traçadas, biotecnológicas, mas, sobretudo, agentes políticos.

O medo do rato, bem como de outros agentes políticos indesejáveis, é um medo do uno que contém o todo. Um só rato nunca é um rato só. Todo rato contém em si a potência de uma infestação. Festim diabólico. Pandemônio, legiões de não humanos que ameaçam conjurar o apocalipse das formas nítidas, das cores brandas. Donde se deduz que todo ceticismo em relação às agências outras contém uma boa dose de assepsia.

\section{AFINAL, VOCÊ É UM HOMEM OU É UM?}

Ser um homem é ser um. Parte única. Composto indissociável. Organismo. Ser homem é indivíduo. Cumpra seu papel, exerça sua função. Seu direito inalienável. Portador de um documento: passaporte, identidade. Documento único. Ser uno e ser pleno. Intangível, constante, possuidor de caráter sólido, ao qual os outros devem se adequar. Ser um é ser sempre um todo.

Um homem não suportaria a existência de duplicidades: 'sujeitinho duas caras aquele hein!' Ambiguidade: substantivo feminino pejorativamente humano para ambivalência. Dilema moderno de ser um entre dois amigos, ser um entre dois amores, ser um e não ser ninguém na multidão. A multidão. Um monte de um que somados não contam dois, pois resultam na unidade, na supressão da diferença. Eis a multidão desnutrida, a multidão societária. Um por todos e todos pela... sociedade, ops! Saciedade! Saciar-se uns aos outros, uns nos outros, diria a posse recíproca de todos por cada um. Bem, se todos se possuem em cada um, onde andará a unidade? De volta à multidão, aquela mais próxima de Spinoza, do Facebook e do Twitter, que retoma sua centralidade para refundar a ação política.

Ser homem é ser igual a ser homem, que é ser igual a ser homem, que é ser igual a ser homem... Não sê-lo é ser antissocial e não pertencer a mankind. Em um franco pensamento selvagem "Tudo se passa como se em nossa civilização, cada indivíduo tivesse como totem sua própria personalidade: ela é o significante do seu ser significado" (Lévi-Strauss 1989:239). Insígnia deste humanismo narcísico, até aqui, o melhor amigo do homem foi nada mais nada menos do que o próprio homem. Ora, é somente restabelecendo as conexões parciais que nos fazem múltiplos, ou seja, divíduos ${ }^{4}$, que poríamos em xeque, evidentemente, a possiblidade de usarmos um artigo indefinido como desígnio da espécie humana. Como poderiam ser os homens apenas um? E o que justificaria um homem conter toda a humanidade?

Da contenção insustentável à vontade humana transborda, assim como o tempo transpassa o corpo. Tempo geracional que já não é mera sucessão agnática, mas que se refere à geração de proto-corpos, de exo-existências, tal qual Serres dedica xs suxs netxs escrevendo à Polegarzinha (2013), aquela que em nossos dias substitui formas pretéritas de aprendizagem progressiva e retilínea por uma reconfiguração do saber que lhe é incorporado simultaneamente a partir de estímulos múltiplos. Para a Polegarzinha ${ }^{5}$, downloads de aplicativos recompõem suas 
habilidades ao passo em que transpassam as fronteiras de seu corpo. Nada de homem-nuvem do Vale do Silício ${ }^{6}$ para Serres esse novo humano pode existir fora de si, pois de acordo com este autor:

Esse ego pode, de corpo e alma, suavemente se confessar, mas igualmente ser guardado, em plástico duro, no bolso. Sujeito, sim; objeto, sim; duplo, então, uma vez mais. Duplo como um paciente, singularmente doente, mas aberto ao olhar médico como uma paisagem. Duplo, competente, incompetente... duplo como um cidadão, público e privado... (Serre 2013: 90).

\section{AFINAL, VOCÊ É UM HOMEM OU?}

Eterna dívida humanista tem-se com a dúvida. Desde cedo submetidos a um regime de escolhas - geralmente equivocadas - a humanidade obtém suas certezas pela negação das incertezas. Na dúvida não siga adiante. Algo como "se beber não dirija", as ciências modernas nos oferecem o "se duvidar não publique o artigo". Pobres de nós, antropólogos, que somos tolhidos do direito de nos embriagar com a literatura. $\mathrm{O}$ que seria dos olhos de ressaca de Capitu se o autor nos legasse como conclusão a comprovação inequívoca de sua traição? A incerteza nos fornece um recurso indiciário, do qual, toda e qualquer ciência social não deveria abrir mão, sob pena de assim fazendo, tornar-se cada vez mais conclusivamente obtusa.

Temos uma dívida histórica com as dúvidas. A falta delas gera a ausência de curiosidade e, consequentemente, a perda de criatividade. Duvidar permite que se relacionem coisas e gentes, humanos e não humanos, que num regime de certezas e de estabilizações vem sendo alijados de sua mutualidade. É a dúvida que nos livrará da epistemologia, sinônimo de ortologia, essa teoria do conhecimento que pressupõe conhecê-lo corretamente.

A dúvida é salutar inclusive quando levanta suspeita sobre aquilo que entendemos como parâmetros de cientificidade. Nem Ciência nem Literatura, a antropologia é uma expertise que procede fundamentalmente através de um complemento de intencionalidade, de motivação, ou melhor, de comprometimento. Ou seja, ela prevê em sua própria composição a lógica de um terceiro incluído. Essa especificidade, evidentemente, nos lega problemas de reprodutibilidade (experimentação) ao optarmos por lidarmos com relatos (experienciações). Dito de outra forma, vivemos o dilema da falta de controle científico, enquanto nos habituamos a lidar com narrativas egressas de situações em que não se está no comando. Por isso, se falamos hoje em uma bem-vinda virada ontológica (Holbraad \& Perdersen 2014), esta se dá, felizmente, porque a antropologia ainda é uma ciência fora de controle. E o marco desta virada só é possível do lado de cá, porque aprendemos com nossos interlocutores, que diariamente viradas ontológicas acontecem acolá.

\section{AFINAL, VOCÊ É UM HOMEM?}

O que cabe dentro de um homem? Termo genérico que expressa em seu gênero, masculino, aquilo que se imiscuiu com a noção de humanidade. Sendo assim, ser humano é ser homem. Condição esta atribuída ao rol de 
indiferenças em relação a outrem da espécie humana. Ora, se em espécie nos aproximamos, essa condição nos separa. Se para um ser humano - qualidade de espécie - é possível identificar igualdade no outro, o fato de "ser" humano - qualitativo de gênero - nem sempre o fez capaz de reconhecer significant otherness. Se não está evidente como pode falar um não humano, a história é pródiga em exemplos quando se trata de calar os menos humanos.

A forma como a partilha entre a condição e a espécie humana foi constituída, como dispôs Ingold (1995), elucida momentos em que estas dimensões se aproximam e se dissociam. Tempos em que a espécie humana era ainda mais restrita: branca, civilizada, euroamericana. Emula-se o abandono destas distinções englobando numa única definição de natureza aqueles que jamais foram de fato e de direito elevados à condição humana. Condição esta que ainda está em jogo para aqueles que devem quotidianamente atestar sua humanidade. A promiscuidade entre a condição humana e a maneira como são concebidos os altos valores do humanismo é reatualizada quando, atônitos, observamos racistas vociferando ofensas especistas em filas de cinema, em gramados de estádios de futebol (padrão FIFA), e até mesmo em recepções de ajuda humanitária em aeroportos brasileiros.

Parece-me que a inclusão de todas e todos que habitam este planeta em uma única espécie irmanada numa certa natureza humana contemplou apenas aqueles cujo uso discricionário da natureza desde sempre favoreceu. Junto ao racismo ambiental, do qual muito se fala, imiscui-se também ao racismo especista que há muito o discurso relativista pensava ter expurgado. Como nos lembra Sahlins (2008), convivemos com a perpétua ilusão ocidental da natureza humana quando enquadramos os modos de existência de outros como sendo desumanos. São numerosos os exemplos que poderíamos acionar. Tomemos apenas um: seria coincidência ouvirmos, através dos principais meios de comunicação, brados sobre um suposto retorno ao estado de natureza no Haiti pós-terremoto de 2010 e, ainda, por contraste, análises que falam em atos que remetem a uma escolha racional, um mês depois, após outro sismo no Chile? Num caso e no outro, a busca por víveres passa a ser narrada como uma luta pela sobrevivência ou como uma atitude plausível de acordo, efetivamente, com os estereótipos elaborados a respeito de quem está envolvido nesta busca. Os graus que estremecem vidas parecem ser mais elevados do que a variação de graus na escala Richter, que, por si, estremecem solos. Tal "rac(s)ísmico" evidencia que o chão que se pisa treme menos que as pessoas que estão sobre ele. 


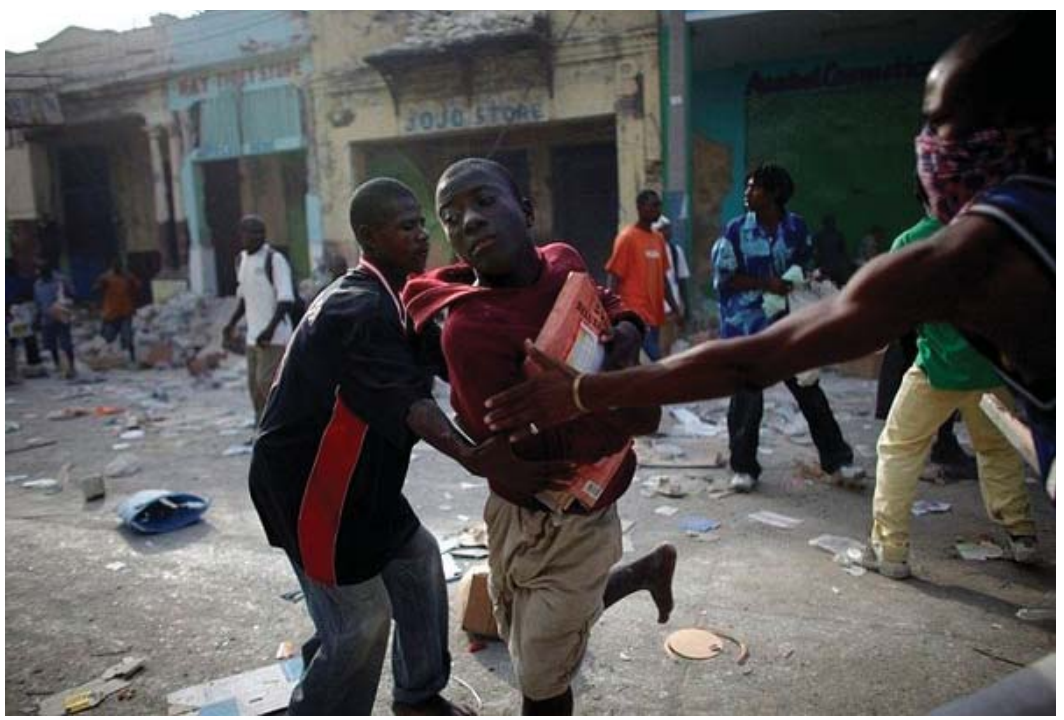

Haiti, janeiro de 2010: 7,0 Mw. Fonte: http://addsite.wordpress.com/2010/01/19/uma-semana-apos-terremoto-haiti-vive-violencia-fome-e-mortes/

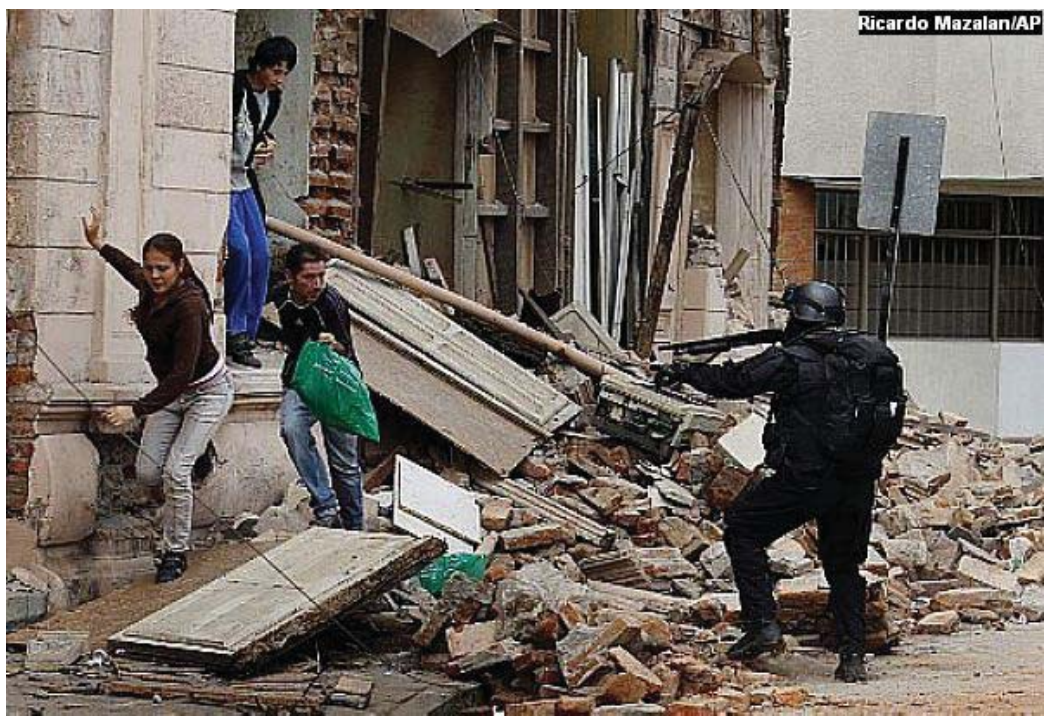

Chile, fevereiro de 2010: 8,8 Mw. Fonte: https://fichacorrida.wordpress.com/2010/03/07/concepcion-cl-orleans-eua-estado-minimo/ 
Um ato desumano é um ato contra a humanidade, mas contra a humanidade de quem? Como um expurgo, eventualmente, a afirmação da dignidade humana pode se valer do empoderamento de uma determinada condição não humana. Trata-se, portanto, de politizar a humanidade colocando em suspenso o que ela tem de humano (entendido como um marcador universal historicamente construído) e que confere a própria humanidade sua incomensurabilidade e sua inegociabilidade.

No que se refere à noção de humanidade como espécie e as suas relações com os demais seres viventes é prudente chamar a atenção para a diferença entre o que descompromissadamente tem sido chamado de interespecificidade e o que aqui situamos como transespecificidade. Essa distinção é importante na medida em que operamos com a ideia de transespeficidade como um dispositivo propício à reflexão e ao tensionamento de determinada condição de espécie, em que mediante um encontro entre espécies distintas (um evento interespecífico), as próprias condições de existência e seus limites de contorno entram em relação. A transformação interespecífica, ou simplesmente a transespecificidade, se dá quando o resultado deste realinhamento relacional é algo diferente daquilo que previamente reconheceríamos como comportamentos, ações, hábitos, performances coligadas aos corpos e características de cada espécie. A transespecificidade é, portanto, um fenômeno anti-atlas.

O império tipológico que governa o universo de relações interespecíficas - por mais ambientalizado que seja o mundo em questão - prevê a existência de espécies taxonomicamente distintas e etologicamente coerentes. Até mesmo os reagrupamentos de espécies consideradas como domésticas, selvagens, de criação etc, pouco nos ajudam a compreender o contexto das relações transespecíficas. Isso se dá porque sob certas circunstâncias um indivíduo de determinada espécie pode, por exemplo, domesticar-se ou asselvajar-se, não por volição intrínseca, mas por entrar em relação. Obviamente, isso conta também para as condições humanas de modo que optamos por não compactuar com qualquer convenção antropocêntrica que entenda, a priori, a existência de indivíduos ou espécies intrínseca e autonomamente coerentes. Ao darmos esse passo, nos aproximamos do que realmente interessa a uma abordagem pós-humanista dos animal studies.

(...) the questions that occupy (human-) animal studies can be addressed adequately only if we confront them on not just one level but two: not just the level of content, thematics, and the object of knowledge (the "animal" studied by animal studies) but also the level of theoretical and methodological approach (how animal studies studies "the animal"). Just because we direct our attention to the study on nonhuman animals, and even if we do so with the aim of exposing how they have been misunderstood and exploited, that does not mean that we are not continuing to be humanist - and therefore, by definition, anthropocentric. (Wolfe 2010: 99).

Ao refazermos nosso percurso para além deste exclusivismo humanista, batizado antropocentrismo, encontramos formas virtuosas de vida não humanas, que, para Bateson, também se fizeram inquilinas em nossa existência: 
De modo geral, não foram os aspectos mais rudes, mais simples, mais animalescos e primitivos da espécie humana que se refletiram no fenômeno natural. Foram, pelo contrário, os aspectos mais complexos, estéticos, complicados e elegantes que refletiram a natureza. Não foram minha ganância, minha determinação e meu assim chamado "animal", meus assim chamados "instintos" e assim por diante que eu estava reconhecendo no outro lado daquele espelho, lá na "natureza". Mais exatamente, eu estava vendo ali as raízes da simetria humana, beleza e feiura, estética, vivacidade e um pouco da sabedoria do ser humano. Sua sapiência, seu encanto corporal e mesmo seu hábito de fazer objetos bonitos são tão "animais" quanto sua crueldade. Afinal de contas, a própria palavra "animal" significa "contemplado com mente ou espírito (animus). (Bateson 1986: 13).

\section{AFINAL, VOCÊ É?}

Escorado em forte teor identitário o verbo ser sustenta-se através de marcadores de estado que promovem a sua substantivação: um ser, o ser. Este se revela, pois, ao imbricar-se com o que já foi dito a respeito da existência una. Sua afirmação consiste na percepção de que outras existências lhe foram abortadas e que toda alteração deve ser contida (Tarde 2007). Ser um ser exclusivo pressupõe a exclusão dos inúmeros não seres. Em face disso, iniciamos nossa altercação ao forjarmos nas relações entre humanos e não humanos uma recomposição daquilo que se denominou social, e fazemos isso por meio de associações em novos coletivos. Novamente, não se tratam de pautas individuais, mas de possessões recíprocas as quais todos (con)têm uns aos outros. Nada e ninguém estariam fora das ações dos outros, fora da alteração, que conformam outras ações e, como pressupunha Gabriel Tarde, todo estado seria um estado alterado.

Deparamo-nos, enfim, com o corolário máximo dos recentes estudos sobre as relações entre humanos e não humanos: o propalado e indigesto enigma acerca das agências não humanas. Ainda que tenham sido severamente criticadas pelos enunciados de determinada ciência social representacionalista as agências não humanas propagamse pelo mundo a revelia do que dizem os sociólogos, os antropólogos, os epistemólogos e de qualquer forma de adestramento intelectual. Afinal, nada mais humano do que a fidelidade canina aos próprios (pre)conceitos.

Despret situa bem a questão:

Chez certains scientifiques étudiant les animaux et, plus particulièrment encore, chez les primatologues, una question semble de plus em plus s'imposer: dans quelle mesure ce que le scientifique observe constitue-t-il une réponse, un jugement, une opinion, de la part de l'animal au sujet de ce que lui propose celui que interroge? Pour certains de ces chercheurs, cette question se pose de manière explicite. Pour d'autres, elle émerge sous des formes moins ouvertes, elle transparaît parfois comme une inquiétude, mais une inquiétude dont je ne peux m'empêcher de penser que les conséquences pourraient être fécondes, pour la recherche, pour le scientifique qui prend cette inquiétude au sérieux et renvoie la question à l'animal et pour les animaux qui sont invités à y répondre. (Despret 2009:7).

A repulsa em lidar com ideias alternativas provém do dogmatismo de que toda e qualquer agência não humana só poderia ser atribuída a, ou projetada através de, uma agência humana. Uma reação de espanto com este argumento triavialista leva-nos a retrucar que ao tratarmos de outras agências nos confrontamos de fato com agências outras, e que estas muito pouco refletem este antropos destituído de relações. 
Se para a sustentação dos argumentos em torno da prevalência ontológica do humano seria preciso que os deslocamentos animais soassem como bizarros disparates animistas, poderíamos, outrossim, contra-argumentar citando um trecho em que Franz Boas, ao pontuar as limitações do método comparativo, indicava a recorrência do mesmo equívoco:

A mera declaração de que o homem primitivo considera os animais dotados de todas as qualidades humanas mostra que a analogia entre muitas qualidades dos animais e dos seres humanos leva à generalização de que todas as qualidades dos animais são humanas. (Boas 2004[1896]:29).

A despeito da centena de anos que os separam, é possível compor o vaticínio de Boas com a perspectiva da primatóloga Bárbara Smuts, segundo a qual

(...) o relacionamento com outros seres enquanto pessoas nada tem a ver com o fato de eles possuírem ou não características humanas. Tem a ver, isto sim, com o reconhecimento de que eles são sujeitos sociais, como nós, cuja experiência idiossincrática e subjetiva de nós desempenha o mesmo papel em suas relações conosco que a nossa experiência subjetiva deles desempenha em nossas relações com eles. Se eles se relacionam conosco como indivíduos, e nós nos relacionamos com eles como indivíduos, é possível para nós ter uma relação pessoal. Se qualquer das duas partes deixa de levar em conta a subjetividade social da outra, tal relacionamento fica impossibilitado. (...) Em outras palavras, quando um ser humano se relaciona com um indivíduo não humano como sujeito anônimo, mais do que como um ser com sua própria subjetividade, é o humano, e não o outro animal, que renuncia à pessoalidade. (Smuts 2002:141-2).

Contudo, seria possível descrever essas agências outras sem nos remetermos as próprias agências/agendas? O mais cético dos modernos ${ }^{9}$ diria que não, e somente através de conceitos intermediários - logicamente humanos - seria possível alcança-las interpretando-as de acordo com a nossa compreensão. Por outro lado, o mais tímido dos não modernos, sem comungar com a partilha epistemológica entre humanos e não humanos, observaria que toda forma de associação deixa um rastro, e todo rastro é fruto de (alter)ações no mundo. Destarte, não haveriam agências isoladas, uma vez que todo agente contém, em si, um reagente; uma vez que em toda ação figura uma reação, e que toda aproximação é uma maneira de repelir o atrito ao levar outro consigo.

\section{AFINAL, VOCÊ?}

Quanto mais nos aproximamos do fim desta digressão mais nitidamente ecoam os brados das "Ciências do Homem". Mas, de que homem se fala a não ser sobre você? Seu foco permanece nesse outro relativo, aquele cuja pretensão é (um) ser absoluto. Qual narcisismo humanista que não permite enxergar o outro além de você! É justamente sobre essa superfície espelhada que assentamos o nosso problema: seria possível sustentar um humanismo para além do que reconhecemos como humano?

Ao falarmos de você, aqui, estamos falando de nós outros (nosotros) e não de outros nós (emaranhados, enosados coletivos). Eufemismo seria um subterfúgio politicamente correto para situarmos o tipo de universalismo 
paroquial das ciências humanas: falamos dos outros, mas considerando que os outros são vocês, nos pegamos falando sozinhos para e sobre nós mesmos. Triste sina de uma epistemologia egocentrada.

Pensar diferente, começa por entender que "vocês" não são "a gente". E como sugeriu Derrida (2002), para realizarmos nossa solidão existencial devemos submeter nossa nudez - cor(pos), peles e pêlos - a olhares outros. Aos olhares que não promovem "vocês", já que

Ele está ao redor de mim. E a partir desse estar-aí-diante-de-mim, ele pode se deixar olhar, sem dúvida, mas também, a filosofia talvez o esqueça, ela seria mesmo esse esquecimento calculado, ele pode, ele, olhar-me. Ele tem seu ponto de vista sobre mim. O ponto de vista do outro absoluto, e nada me terá feito pensar tanto sobre essa alteridade absoluta do vizinho ou do próximo quanto os momentos em que eu me vejo visto nu sob o olhar de um gato. (Derrida 2002: 28)

Através deste olhar felino, que outrora espreita depois te devora, "O animal nos olha, e estamos nus diante dele. E pensar começa talvez aí." (Derrida 2002: 57) Logo, se "vocês" não são "a gente", proclama-se "a gente é o bicho!" e busca-se nos animais não humanos bons marcadores naturais - factishes - que nos auxiliam a pensar criticamente a antropologia, travestida de Ciência, na medida em que denunciam a presença de dispositivos naturalistas em seu cerne. E ainda, como explana Thomas:

La médiatisation homme/homme par l'animal, la médiatisation animal/animal par l'homme, la médiatisation homme/ animal par l'animal ou par l'homme pourraient bien constituer une dimension privilegiée (...) des sciences humaines renouvelées avec l'institution d'une anthropologie de l'animal qui peut, à ce propos, nous apprendre beaucoup sur I'homme, se angoisses, ses esperances. (Thomas 2014:122).

\section{AFINAL?}

Afinal, o advérbio restante resume aquilo o que temos feito até agora e o que será possível fazer daqui pra frente. "Você é um homem ou é um rato?" é uma construção marcadamente humana a ponto de não nos servir de inspiração para a redenção das ciências sociais. Devemos apenas nos dirigir a ela como um escárnio a nossa autossuficiência para excluir tudo aquilo que não caberia dentro do nosso humanismo, a saber, as agências não humanas, as vivências feministas, os afetos plurais, as estéticas multicor, as ciências imprevisíveis, os pluriversos ${ }^{10}$ etc. Recorrentemente agindo como uma cobaia de irrefletido humanismo, a antropologia é instada nesta ocasião a não se acovardar escondendo-se na sombra de uma (pré)determinada imagem de homem.

Posto que iniciei com um desafio, "Afinal, você é um homem ou é um rato?", o qual pretendi desconstruir no transcorrer destas linhas, seria previsível que concluísse com uma máxima do reverso da medalha: "Quanto mais conheço os humanos, mais gosto dos meus bichos!". Entretanto, este tipo de proposição não me parece satisfatória quando o que está em jogo é o imperativo de levantar uma hipótese que questione certo humanismo que recai sobre a antropologia e sobre as ciências sociais. Preferir os animais aos humanos não resolverá os problemas condensados na grande divisão entre sociedade e natureza (que em nosso caso revelam-se como arenas epistêmicas distintas entre humanos e animais não humanos), tampouco questionará as noções de humanidade que 
têm sido dolosamente erigidas. A opção pelos animais em detrimento daqueles que chamamos humanos, quando histórica e politicamente deveríamos denunciá-los como Homens (de espécie, gênero e classe bem definidas), revela outra faceta do pensamento humanista, pautado igualmente num valor discricionário que configura outra forma de especismo, agora fetichista animalista, como vem a demonstrar Haraway:

Commonly in the US, dogs are attributed with the capacity for "unconditional love." According to this belief, people, burdened with misrecognition, contradiction, and complexity in their relations with other humans, find solace in unconditional love from their dogs. In turn, people love their dogs as children. Im my opinion, both of these beliefs are not only based on mistakes, if not lies, but also they are in themselves abusive - to dogs and to humans. A cursory glance shows that dogs and humans have always had a vast range of ways of relating. But even among the pet-keeping folk of contemporary consumer cultures, or maybe especially among these people, belief in "unconditional love" is pernicious. If the idea that man makes himself by realizing his intentions in his tools, such as domestic animals (dogs) and computers (cyborgs), is evidence of a neurosis that I call humanist technophiliac narcissism, then the superficially opposed idea that dogs restore human beings' souls by their unconditional love might be the neurosis of caninophiliac narcissism. Because I find the love of and between historically situated dogs and humans precious, dissenting from the discourse of unconditional love matters. (Haraway 2003: 33).

Nem a projeção de amores e afetos humanos sobre os animais e nem a (auto)comiseração por vê-los como bodes expiatórios ajudariam a apontar para as condições assimétricas dos acordos prefixados entre humanos e não humanos. Configurações que legitimaram a posse e o domínio de uns pelos outros. Em Sharing suffering (2008), Haraway critica o humanismo representacionalista pautado na lógica do sacrifício, pois este não nos ajudaria a deter as "maquinas de matar" já que não questiona as bases históricas e materiais sobre as quais se fez possível escravizar e apropriar-se dos corpos "menos humanos". Donde se deduz que diante desta lógica de antropomorfização compulsória, o que se anuncia como subjetividade poderia muito bem sancionar-se como o mais novo ato institucional da política humanista, pois ali a perspectiva do sujeito passaria a ser a sua própria sujeição à qualidade de objeto quase humano. Aqui a lógica do sacrifício pode ser encontrada nos discursos de divulgação dos direitos dos animais que afirmam seu fundamento ético e moral aproximando sujeitos animais de sujeitos humanos. Doravante, boa parte dos problemas que envolviam os direitos humanos passam a ser projetados sobre os direitos dos animais, agravando a tensão já existente no multiculturalismo por não se permitir elencar dimensões ontológicas descentradas do elemento humano. Visto de outra forma, conceber que os animais (categoria ampla e genérica que não nos diz muita coisa fora de uma relação) têm direitos não passa, ou não deveria passar, pela sua humanização. Os animais e os humanos possuem seus direitos, reconhecidos mutuamente, em relações interespecíficas. Mas para reconhecer isso é preciso entender que não pode haver uma única instância normativa onipotente regendo os direitos dos animais ${ }^{11}$. 


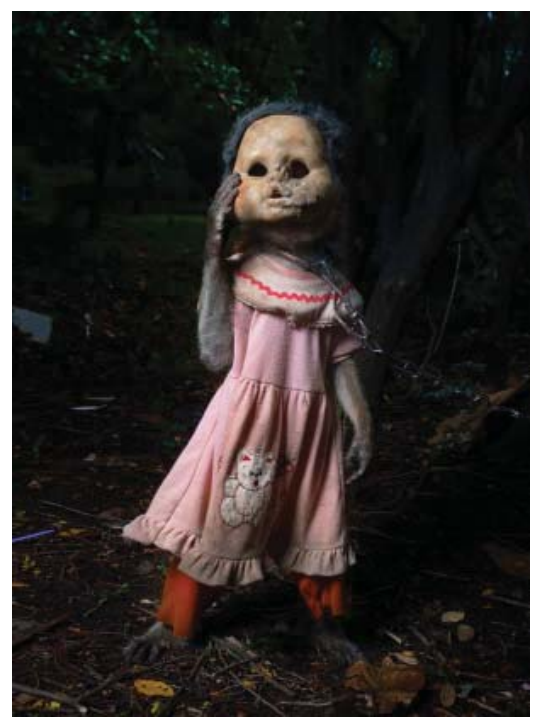

Pertu-Saska, Untitled, $90 \times 70 \mathrm{~cm}$. A Kind of You (2013)

Fonte: http://www.perttusaksa.com/ works/a-kind-of-you-2013

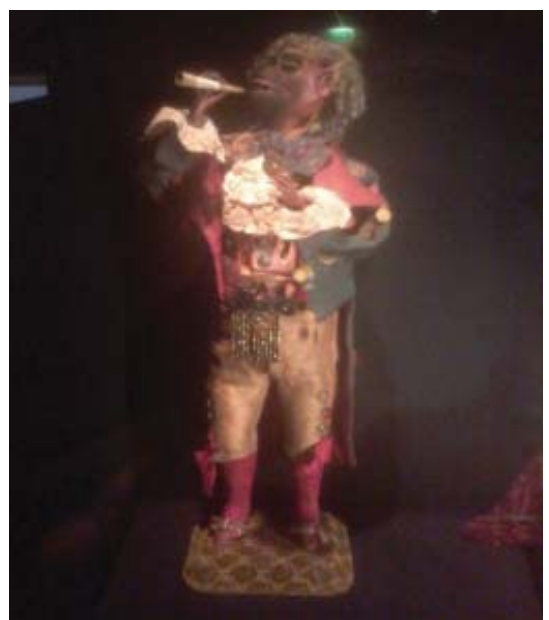

Automate à musique, Le singe fumeur habillé en Incroyable, realisé par Lambert, 1890 (Musée de Arts et Métiers,

Paris).
Como as bonecas-crianças-primatas-escravas (a ordem dos fatores não altera o produto) retratadas por Pertu-Saska, nas favelas de Jakarta, o amor ao próximo é concebido como amor próprio, e no ocidente a história da servidão é reescrita na busca por animais de companhia como uma forma de compensar toda a ausência causada pelo individualismo metropolitano. Contudo, a doença não sana e a solidão não cessa, pelo contrário, elas ampliam seu espectro contagioso ${ }^{12}$. Assim, reafirma-se, perversamente, o pacto colonial em que o racismo, o sexismo e o especismo coligam-se por trás das mesmas máscaras que outrora enfeitavam as luzes da ribalta europeia. Como num golpe do tempo as tecnologias corporificadas dos autômatos europeus do século XIX reverberaram as mesmas políticas antropocêntricas que tornam possíveis a mendicância animal na Indonésia contemporânea.

Em ambos os casos, a fábula do animal-máquina revela-se: um coração pulsante acorrentado e uma engrenagem cuja tração é a mecânica do exclusivismo humano. Nossa técnica e nossa compaixão estão fundadas sobre as mesmas bases da miséria de uns pelo prazer de outros. O regozijo do que apressadamente chamamos de "Homem ocidental" é, portanto, a busca pelo próprio espelhamento. Domínio e fé, repulsa e desejo, o Homem fez o homem a sua imagem e semelhança.

\section{A REUNIÃO GERAL DOS RATOS}

Uma expressão comum ao jargão das relações entre humanos a animais, o abismo, que antes separava estes daqueles, atualmente, causa vertigem ao humanismo circunstanciado em uma noção específica de Homem. Como transpô-lo continua sendo um desafio, como pondera o velho rato porta-voz da moral da história nas fábulas europeias ${ }^{13}$ :

Uma vez os ratos, que viviam com medo de um gato, resolveram fazer uma reunião para encontrar um jeito de acabar com aquele eterno transtorno. Muitos planos foram discutidos e abandonados. No fim um rato jovem levantou-se e deu a ideia de pendurar uma sineta no pescoço do gato; assim, sempre que o gato chegasse perto eles ouviriam a sineta e poderiam fugir correndo. Todo mundo bateu palmas: o problema estava resolvido. Vendo aquilo, um rato velho que tinha ficado o tempo todo calado levantouse de seu canto. $\mathrm{O}$ rato falou que o plano era muito inteligente, que com 
toda certeza as preocupações deles tinham chegado ao fim. Só faltava uma coisa: quem ia pendurar a sineta no pescoço do gato? (Esopo 1994:18).

O sarcasmo, anteriormente anunciado, se impõe ao nos darmos conta de que nesse momento não será através de suas estratégias nem de seus valores que os humanos vencerão o abismo - esta verdadeira barreira natural. Enquanto certos "Homens" se esmeram em construir pontes, os ratos já chegaram do outro lado. Igualmente, não seria sob a condição de ser humano que poderia escolher entre um homem ou um rato, mas pelo desejo da condição rato que me propicia associar-me oportunamente a humanos e não humanos.

Como num passado em que os ratos proliferavam-se nas trevas, sustentando hipóteses de geração espontânea, foi necessário que luzes se fizessem lançar para qualificar tal equívoco. As mesmas luzes parecem hoje servirem apenas a isso: qualificar equívocos a medida em que nos cegam com a sua Verdade. Em compensação, e a sua revelia, os ratos seguem se reproduzindo no lixo. A questão é que esta forma de conhecer, caracterizada pelo humanismo iluminista, determina menos a maneira na qual os seres se multiplicam do que as condições em que cada ser pode existir. Em síntese, vive-se em um mundo que produz mais lixo do que alternativas.

No entanto, recebemos a notícia de que há resistências às formas de apropriação humana do mundo. $\mathrm{O}$ animalismo sai, portanto, de seu imanente estado de natureza e anuncia que a lei da selva torna-se, enfim, guerrilha urbana. Os eventos de libertação de cobaias animais, como o resgate dos beagles ocorrido no Instituto Royal em 2013, apontam para um horizonte além da compaixão projecional. Contrariamente, ao agirem com paixão ao resgatarem esses cães, essas pessoas salvam os humanos de seu próprio humanismo. Elas indicam um germe de contestação do acordo tácito subscrito há séculos pelo humanismo, segundo o qual os fins humanitários justificariam os meios não-humanos. Este movimento demanda novos acordos menos eloquentes - talvez -, porém mais promissores na medida em que recompõem a prática da ciência dentro de uma pauta política. E, por conseguinte, ao recuperar as incertezas na ciência restituir-se-ia a diplomacia na política. 


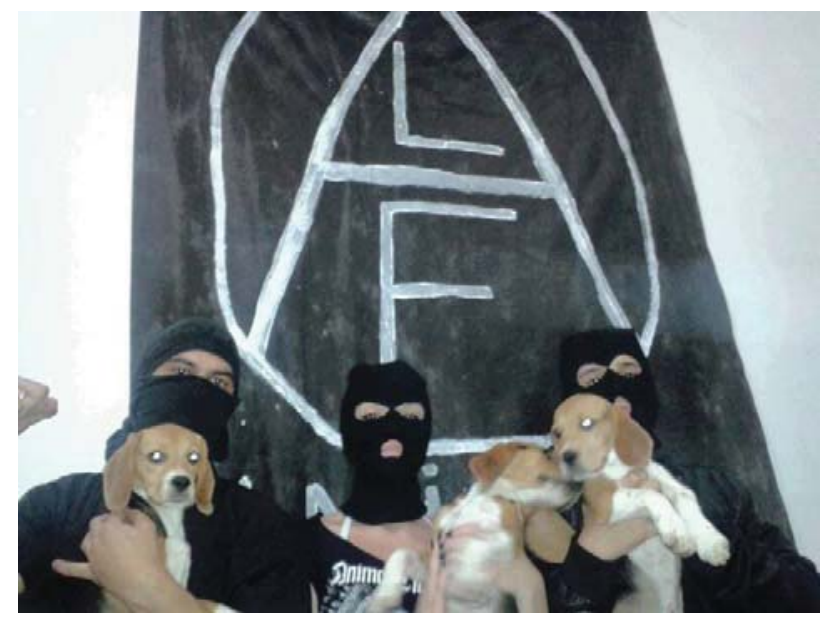

Black Blocs e a libertação dos beagles do Instituto Royal (SP, 2013).

Fonte: http://www.veganguerilla.de/news-zu-tierbefreiungdemo-instituto-royal-dichtmachen/

Posto que, contrariando o prognóstico da velha fábula, já existem os voluntários para "pendurar a sineta no pescoço do gato"; nos cabe agora optar pela reforma do edifício humanista ou pela sua condenação em virtude da falência de seus alicerces. Ao que parece, o rato já decidiu.

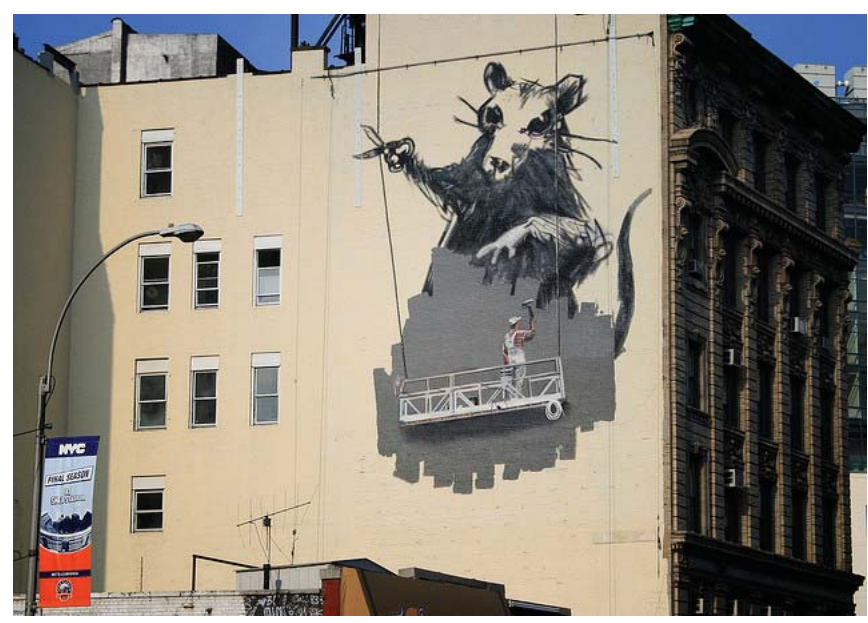

Banksy (Chinatown, New York) Fonte: http://www.djibnet.com/photo/mural/banksyrat-mural-on-canal-street-chinatown-new-yorkcity-2928287400.htm

Guilherme José da Silva e Sá é doutor em Antropologia Social pelo Museu Nacional - Universidade Federal do Rio de Janeiro e professor adjunto do Departamento de Antropologia da Universidade de Brasília. 


\section{NOTAS}

1 Versão preliminar deste texto foi apresentada na IV Reunião de Antropologia da Ciência e da Tecnologia. Unicamp. Campinas, 2013.

2 Agradeço a leitura cuidadosa de Laura Pérez Gil e Antonádia Monteiro Borges e suas valiosas contribuições para esse texto. Agradeço também aos meus alunos que a cada dia me ensinam que é aos poucos que o "rato rói a roupa do rei de Roma"!

3 Questão que Lévi-Strauss perseguiu de um lado a outro do oceano Atlântico, da França aos EUA e especialmente durante sua passagem pelo Brasil.

4 Divíduo no sentido evocado por Strathern (2006) no qual determinado conceito de pessoa é composto por relações plurais, contrariamente à percepção de uma integralidade individual.

5 Em referência à nova escrita digital-virtual-portátil com os polegares, pictografia dos novos humanos.

6 Aquele que acumula suas habilidades, conhecimentos, informações, enfim, que o constituem, fora da materialidade de um corpo.

7 "Outridades significantes", em uma livre tradução para o conceito de Donna Haraway.

8 Aquela que vê no estatuto das representações sociais, estas sim produções humanas ("modernas", "ocidentais", diga-se de passagem), o limite para as formas de atuação dos "outros" (não-humanos, taxonomicamente falando, ou "menos humanos", politicamente discriminando). Para uma discussão ampliada sobre o assunto ver Latour (2012).

9 Perdoem-me a redundância entre criatura e criador, ou, dito de outra maneira, teria sido a modernidade que inventou o ceticismo ou o ceticismo que criou a modernidade?

10 Noção acionada por Gabriel Tarde em Monadologia e Sociologia (1895) para designar o ambiente de existência (e, por que não, a ecologia?) das mônadas.

11 E tampouco os direitos humanos.

12 Sobre o tema dos cuidados psicológicos direcionados aos pets ver trabalho de Jean Segata (2012).

13 Estes registros literários elencam metáforas narrativas que expressam a mesma centralidade da perspectiva humana que os autômatos zoomórficos. 


\section{REFERÊNCIAS BIBLIOGRÁFICAS}

BATESON, Gregory. 1986. Mente e Natureza: a unidade necessária. Rio de Janeiro: Editora Francisco Alves.

BOAS, Franz. 2004 [1896]. "As limitações do método comparativo da Antropologia". In: C. Castro. (org.). Antropologia Cultural. Rio de Janeiro: Jorge Zahar.

DERRIDA, Jacques. 2002. O animal que logo sou. São Paulo: Unesp.

DESPRET, Vinciane. 2009. Penser comme un rat. Versailles: Éditions Quae.

ESOPO. 1994. Fábulas de Esopo. (trad. Heloísa Jahn). São Paulo: Companhia das Letrinhas.

HARAWAY, Donna. 2003. The Companion Species Manifesto: Dogs, people, and significant otherness. Chicago: Prickly Pardigm Press.

2008. When Species Meet. Minneapolis: University of Minnesota Press.

HOLBRAAD, Martin; PEDERSEN, Axel Morten (2014). "The Politics of Ontology". In: Fieldsights - Theorizing the Contemporary, Cultural Anthropology Online, January 13, 2014. Recuperado em 20 de julho de 2014 de http:// www.culanth.org/fieldsights/461-the-politics-of-ontology

INGOLD, Tim. 1995. "Humanidade e Animalidade". Revista Brasileira de Ciências Sociais 10 (28): 39-54.

LATOUR, Bruno. 2012. Reagregando o Social: uma introdução à Teoria do Ator-Rede. Bauru: Edusc; Salvador: EDUFBA.

LÉVI-STRAUSS, Claude. 1989. O Pensamento Selvagem. Campinas: Papirus.

2012. A Antropologia Diante dos Problemas do Mundo Moderno. São Paulo: Companhia das Letras.

SAHLINS, Marshall. 2008. The Western Illusion of Human Nature. Chicago: Prickly Paradigm Press.

SEGATA, Jean. 2012. “Os cães com depressão e os seus humanos de estimação". Anuário Antropológico 2012 (II):177-204.

SERRES, Michel. 2013. A Polegarzinha: uma nova forma de viver em harmonia e pensar as instituições, de ser e de saber. Rio de Janeiro: Bertrand Brasil.

SMUTS, Barbara. 2002. "Reflexões". In: J. M. COETZEE. A Vida dos Animais. São Paulo: Companhia das Letras. STRATHERN, Marilyn. 2006. O gênero da dádiva. Problemas com as mulheres e problemas com a sociedade melanésia. Campinas: Editora da Unicamp.

TARDE, Gabriel. 2007. Monadologia e sociologia e outros ensaios (org. Eduardo Viana Vargas). São Paulo: Cosac Naify.

THOMAS, Louis-Vincent. 2014. “L'homme et le rat. Vers une anthropologie de l'animal”. Prétentaine. Quel animal? 29/30.

WOLFE, Cary. 2010. What is Posthumanism? Minneapolis: University of Minnesota Press. 


\section{Afinal, você é um homem ou um rato?}

\section{RESUMO}

O artigo, que toma a forma de ensaio crítico, tem como mote de argumentação uma prosaica provocação "Afinal, você é um homem ou um rato?". Em torno dela surgem como principais pontos a antropologia dos animais, as relações interespecíficas e o pós-humanismo. O texto é igualmente uma peça de reflexão a respeito dos compromissos assimétricos históricos que foram forjados no cerne do pensamento humanista. As referências são propositalmente apócrifas a fim de permitir por um lado o assentamento de aforismos e, por outro, possibilitar a livre apropriação do texto e sua recomposição pelo leitor. A crítica ao antropocentrismo e ao representacionalismo, que ora se apresenta às ciências sociais, é feita através de uma estratégia que centraliza a alteração na forma de escrever e de narrar, como forma de expressão de um posicionamento comprometido com a descentralização da hegemonia humana.

PALAVRAS-CHAVE: pós-humanismo; animais; antropologia; interespecificidade; crítica do humanismo.

\section{After all, what are you, a man or a mouse?}

\section{ABSTRACT}

This paper, which takes the form of a critical essay, has the motto argument of a prosaic provocation "After all, what are you, a man or a mouse?". Around this question, the texts approaches the issues of the anthropology of animals, the interspecific relationships and the posthumanism. The text also brings some reflection on the historical and asymmetric commitments forged in the heart of humanist thought. References are purposely apocryphal in order to, firstly, settle down aphorisms and, secondly, allow the free appropriation of the text and its reassembling by the reader. A critique of anthropocentrism and representationalism - presented here for the social sciences - is made through a strategy centralized on changing the ways of writing and narrating, as well as an expression of an active commitment to the descentralization of human hegemony.

KEY WORDS: posthumanism; animals; anthropology; interespecificity; critique of humanism. 